\title{
Development of Mathematical Models to Optimize Weld Penetration Area of Mild Steel in Gas Tungsten Arc Welding
}

\author{
Ofoeyeno. ${ }^{1}$ Achebo .J.I $\mathrm{I}^{2}$ and Ozigagun $\mathrm{A}^{3}$ \\ 1, 2, ${ }^{3}$ Department of Production Engineering, Faculty of Engineering, \\ University of Benin, P.M.B 1154, Benin City, Edo State Nigeria
}

\begin{abstract}
Tungsten Inert Gas (TIG) weld quality and mechanical properties are systematically structured by the bead width, reinforcement and penetration size. This study has developed a mathematical model using the second order quadratic polynomial model to select the best setting for the process parameters to produce the maximum penetration area in TIG welding. The set of experiment samples was produced from mild steel plates guided by a central composite design experimental plan. The results obtained revealed that the second order quadratic polynomial equation is the best fit model that can accurately explain the relationship between the input and the output parameters. The results possessed good statistical sufficiency, having a very good strength for predicting the target response. The prediction strength and models reliability factor are in reasonable agreement with each other, the surface plots showed the combined interaction of input parameters on the response, and the ANOVA results revealed that the penetration area is very sensitive to the current parameter. The mathematical models developed have a high goodness of fit, adequate signal,strength which can explain and predict the penetration area.
\end{abstract}

Keywords:- penetration area, models, Response Surface Methodology,, Tungsten Inert Gas, Welding,quality.

\section{INTRODUCTION}

Gas tungsten arc welding (GTAW) is known to be the best quality means for metal fabrication. Different grades of steel product can be constructed using this method for higher quality weld at minimum cost[1]. The integrity of the TIG weld can be determined by the quality of the weld bead geometry, because the mechanical properties of welded joints are influenced by the morphology of the weld bead profile. The penetration area, bead height and reinforcement height all add up to make the bead geometry which gives the welded joint the capacity and strength to carry the designed load.. The shape and size of welds are known to exert a major influence on stress distribution during the solidification and shrinkage periods. The welding current has been identified as the main parameter controlling the heat input required to melt the base metal and the filler rod. Combining the process parameters optimally guarantees a greater weld, some welding operators used trial and error techniques to combine these parameters which lacks statistical integrity of explaining the relationship between the input and response. A poor weld bead geometry can result to structural failures of welded joints, which is known to be the key factor controlling the strength and quality of the weld. Research studies have shown that this problem be reduced by proper combination of the welding process factors such as power source, polarity, voltage setting, flow rate of the shielding gas and current[2].A study on TIG aspect ratio reveals that large aspect ratios has a negative effect on the quality of the welded joint, the study obtained optimal results that will produce minimum aspect ratios as large aspect ratio can induce cracks and residual stresses into fusion zone of the weld joint. To conduct an accurate experimental procedure an optimal experimental design is needed, computer programs like design expert and minitab can employed to develop the experimental matrix. The central composite design is found most suitable when compared to other designs ,the results produced minimum aspect ratio of $0.646[3]$. Weld quality can be maximized by controlling the deposition rate of the molten metal deposit,an appropriate level is best to sustain the strength and load bearing capacity of the joint. Experimental and statistical studies was carried out to produce an optimal deposition rate. The solution obtained shows that the input factors have very robust effect on the deposition rate. The models showed a high predictive strength value of $91 \%$. The model produced numerically obtained optimal solution of current of $160.00 \mathrm{Amp}$, voltage of 20 volts and a gas flow rate of $17 \mathrm{~L} / \mathrm{min}$ produces a welded material having deposition rate of $0.4637 \mathrm{~kg} / \mathrm{hr}$ [4]. Cost reduction is also as important as the quality of the products in the metal construction industry,so prediction and simulation of the desired properties is of great importance. There are so many predictive simulation tools today, but understanding their strength , applicability,and compatibility with certain welding data is also of great concern. Fuzzy logic technique is one very reliable tool that can be used to effectively carryout predictive study. This expert method was employed to predict the weld penetration size factor of a weld considering welding speed current and voltage which gave a very good result. [5]. An examination of the tensile strength and strain properties of mild steel plates was conducted which used the artificial neural network to predict this responses in this study. the Scanning Electron Microscope analysis was done showing a consistently distributed grain sizes in the weld.the base metal chemistry has a make up of nickel,iron chromium and molybdenum [6]. 
Research has shown that one of the practical ways to produce better weld qualities is to optimize the input process factors. The effects of current, voltage and gas flow rate on the tensile strength was examined, the Artificial neural network (ANN) Model was employed to analyze the experimental results. The best validation performance is 0.48429 and occurred at epoch five (5). The coefficient of correlation value which measures the closeness of the network output to the experimental output are as follows, training shows of $99.9 \%$ closeness , validation shows $99.4 \%$ correlation and $89.8 \%$ for testing respectively. The overall $\mathrm{R}$-value is shown to be $98.7 \%$. [7].

\section{RESEARCH METHODOLOGY}

In this study an optimum experimentation to maximize penetration area was conducted. Gas tungsten arc welding process was used to join the weld specimen made of low carbon steel. The first step taken was to cut the mild steel coupons ,sand paper and bevel the edges. Using the optimal experimental matrix as a guide, five set of welded sample was made for each experimental run which amounted to a total of one hundred weld samples.

\section{Identification of Range of Input Parameters}

The input factors used in this research study are shielding gas flow rate, current, and speed and voltage. The range is captured in Table 1

\begin{tabular}{|c|c|c|c|c|}
\hline Parameters & Unit & Symbol & Coded value & Coded value \\
\hline & & & Low(-1) & 240 \\
\hline Current & Amp & A & 180 & 22 \\
\hline Gas flow rate & Lit/min & F & 18 & 24 \\
\hline Voltage & Volt & V & 3 & 4.5 \\
\hline Welding speed & $\mathrm{cm} / \mathrm{min}$ & $\mathrm{S}$ & & \\
\hline
\end{tabular}

Table 1:- Range of input process parameters

\section{Method of Data Collection}

The central composite design matrix was developed using the design expert software, producing 25experimental runs. The input parameters and output parameters make up the experimental matrix, and the responses recorded from the weld samples were used as the data. Table2 shows the central composite design matrix. Response surface methodology design can either be carried out using the Box-Behnken Design or the Central Composite Design. In this article, the Central Composite Design was adopted. Central Composite design is also a response surface method (RSM) as stated earlier which apart from its three level factors has axial point (also known as star point), and this axial point increases the number of levels to five levels to give the experimental design flexibility and robustness. In Central Composite Design the minimum numbers of factors it can accommodate is two.

\begin{tabular}{|c|c|c|c|c|c|}
\hline \multirow{2}{*}{$\begin{array}{l}\text { Test } \\
\text { Runs }\end{array}$} & \multicolumn{4}{|c|}{ INPUT PARAMETERS } & \multirow{2}{*}{$\begin{array}{c}\text { OUTPUT PARAMETER } \\
\text { AP } \\
\mathrm{mm}^{2}\end{array}$} \\
\hline & $\begin{array}{l}\text { Current } \\
\text { (I) }\end{array}$ & $\begin{array}{l}\text { Voltage } \\
\text { (V) }\end{array}$ & $\begin{array}{l}\text { Welding Speed } \\
\text { (S) } \mathrm{mm} / \mathrm{sec}\end{array}$ & $\begin{array}{l}\text { Gas Flow Rate } \\
\text { (GFR) L/min }\end{array}$ & \\
\hline 1 & 120 & 16 & 2.00 & 10 & 6.78 \\
\hline 2 & 120 & 17 & 2.25 & 11 & 9.86 \\
\hline 3 & 120 & 18 & 2.65 & 12 & 4.86 \\
\hline 4 & 120 & 19 & 3.00 & 13 & 7.54 \\
\hline 5 & 120 & 20 & 3.25 & 14 & 5.72 \\
\hline 6 & 130 & 16 & 2.25 & 12 & 9.51 \\
\hline 7 & 130 & 17 & 2.65 & 13 & 8.42 \\
\hline 8 & 130 & 18 & 3.00 & 14 & 8.67 \\
\hline 9 & 130 & 19 & 3.25 & 10 & 6.73 \\
\hline 10 & 130 & 20 & 2.00 & 11 & 8.43 \\
\hline 11 & 140 & 16 & 2.65 & 14 & 5.29 \\
\hline 12 & 140 & 17 & 3.00 & 10 & 10.75 \\
\hline 13 & 140 & 18 & 3.25 & 11 & 7.58 \\
\hline 14 & 140 & 19 & 2.00 & 12 & 9.05 \\
\hline 15 & 140 & 20 & 2.25 & 13 & 4.36 \\
\hline 16 & 150 & 16 & 3.00 & 11 & 8.55 \\
\hline 17 & 150 & 17 & 3.25 & 12 & 5.84 \\
\hline 18 & 150 & 18 & 2.00 & 13 & 4.77 \\
\hline
\end{tabular}


ISSN No:-2456-2165

\begin{tabular}{|l|l|l|l|l|l|}
\hline 19 & 150 & 19 & 2.25 & 14 & 10 \\
\hline 20 & 150 & 20 & 2.65 & 13 & 9.49 \\
\hline 21 & 160 & 16 & 3.25 & 14 & 10.53 \\
\hline 22 & 160 & 17 & 2.00 & 10 & 8.94 \\
\hline 23 & 160 & 18 & 2.25 & 11 & 6.33 \\
\hline 24 & 160 & 19 & 2.65 & 12 & 8.58 \\
\hline 25 & 160 & 20 & 3.00 & 7.44 \\
\hline
\end{tabular}

Table 2:- Experimental data

\section{Experimental procedure}

Mild steel plate was used as the base material for the single-pass surface welding with a direct current of reverse polarity. The samples were grinded, sand cleaned and etched to get a fine edge because sample has to be free from grease and dirt..100 pieces of mild steel coupons was produced for this experiment using $100 \%$ argon gas as the shielding gas. In this process the tungsten non consumable electrode having diameter $3 \mathrm{~mm}$ was used alongside a 2 $\mathrm{mm}$ diameter filler metal ER309Lthe responses were measured and recorded respectively.

\section{Testing the Adequacy of the Models Developed}

The analysis of variance (ANOVA) was used to test the adequacy of the models developed. The statistical significance of the models developed and each term in the regression equation were examined using the sequential $\mathrm{F}$ test, lack-of-fit test and other adequacy measures ( i.e. $\mathrm{R}^{2}$, Adj- $\mathrm{R}^{2}$ Pred. $\mathrm{R}^{2}$ and Adeq. Precision ratio) using the same software to obtain the best fit. The Prob. > F (sometimes called p-value) of the model and of each term in the model can be computed by means of ANOVA. If the Prob. > F of the model and of each term in the model does not exceed the level of significance ( say a $=0.05$ ) then the model may be considered adequate within the confidence interval of (1-a). For the lack-of-fit test, the lack of fit could be considered insignificant if the Prob. > F of the lack of fit exceeds the level of significance.

\begin{tabular}{|c|c|c|c|c|}
\hline $\begin{array}{c}\text { Variation } \\
\text { Source }\end{array}$ & $\begin{array}{l}\text { Degree of } \\
\text { FreedomDf }\end{array}$ & $\begin{array}{c}\text { Sum of Squares } \\
\text { sS }\end{array}$ & $\begin{array}{c}\text { Mean Square } \\
\text { MS }\end{array}$ & $\begin{array}{c}\text { Fisher Ratio } \\
\text { F-value }\end{array}$ \\
\hline Enror of residuals & $n-2$ & $S S E=\sum_{i=1}^{L} \sum_{j=1}^{\mathrm{E}}\left(y_{i}-\hat{y}_{i}\right)^{2}$ & $M S E=\frac{S S E}{n-2}$ & \\
\hline Regression & 1 & $S S R=\sum_{j=1}^{c} \sum_{j=1}^{E}\left(\hat{y}_{\gamma}-\bar{y}\right)^{2}$ & $M S R=\frac{S S R}{1}$ & $F=\frac{M S R}{M S E}$ \\
\hline Lack of fit & $C-2$ & $\operatorname{SSL} F_{t}=\sum_{i=1}^{c} \sum_{j=1}^{\delta}\left(\bar{y}_{\theta}-\hat{y}_{v}\right)^{2}$ & $M S L F=\frac{S S L F}{c-2}$ & $F^{\prime}=\frac{M S L F}{M S P E}$ \\
\hline Total & $n-1$ & $S S T D=\sum_{i=1}^{c} \sum_{j=1}^{\varepsilon}\left(y_{y}-\bar{y}_{v}\right)^{2}$ & - & - \\
\hline
\end{tabular}

Table 3:- Analysis of variance components.

\section{RESULTS AND DISCUSSION}

In this study, an attempt is made to develop a second order mathematical model to explain the relationship between; current (I), voltage (V) and gas flow rate to reduce fume concentration and electrode melting rate, using response surface methodology (RSM).The first step taken in modeling of an RSM model is to validate the suitability of the quadratic model in analyzing the experimental data, and the the sequential model sum of squares was calculated to check for the best model,electrode melting ratel sum of squares is in table 4

\begin{tabular}{|c|c|c|c|c|c|c|}
\hline & Sum of & & Mean & F & p-value & \\
\hline Source & Squares & Df & Square & Value & Prob $>$ F & \\
\hline Mean vs Total & 1718.54 & 1 & 1718.54 & & & 0.0608 \\
\hline Linear vs Mean & 53.94 & 4 & 13.48 & 2.59 & 0.8452 & \\
\hline 2FI vs Linear & 15.74 & 6 & 2.62 & 0.44 & 6.0001 & Suggested \\
\hline Quadratic vs 2FI & 108.12 & 4 & 27.03 & 66.93 & $<0.0485$ & Aliased \\
\hline Cubic vs Quadratic & 4.92 & 8 & 0.61 & 3.77 & 0.0485 & \\
\hline Residual & 1.14 & 7 & 0.16 & & & \\
\hline Total & 1902.40 & 30 & 63.41 & & & \\
\hline
\end{tabular}

Table 4:- Sequential model sum of square for weld penetration area 
In table 4 the quadratic model was selected as the most suitable as having the lowest p-value $<0.0001$.In assessing the strength of the quadratic model for the weld penetration area one way analysis of variance (ANOVA) table was generated which is presented in table 5

\begin{tabular}{|c|c|c|c|c|c|c|}
\hline & Sum of & & Mean & $\mathrm{F}$ & p-value & \\
\hline Source & Squares & Df & Square & Value & Prob $>F$ & \\
\hline Model & 177.80 & 14 & 12.70 & 31.45 & $<0.0001$ & Significant \\
\hline A-current & 31.42 & 1 & 31.42 & 77.80 & $<0.0001$ & \\
\hline B-voltage & 2.76 & 1 & 2.76 & 6.84 & 0.0195 & \\
\hline C-welding speed & 0.53 & 1 & 0.53 & 1.32 & 0.2682 & \\
\hline D-gas flow rate & 19.22 & 1 & 19.22 & 47.60 & $<0.0001$ & \\
\hline $\mathrm{AB}$ & 2.24 & 1 & 2.24 & 5.53 & 0.0327 & \\
\hline $\mathrm{AC}$ & 2.48 & 1 & 2.48 & 6.14 & 0.0256 & \\
\hline $\mathrm{AD}$ & 2.36 & 1 & 2.36 & 5.83 & 0.0289 & \\
\hline $\mathrm{BC}$ & 6.08 & 1 & 6.08 & 15.05 & 0.0015 & \\
\hline $\mathrm{BD}$ & 0.33 & 1 & 0.33 & 0.82 & 0.3799 & \\
\hline $\mathrm{CD}$ & 2.27 & 1 & 2.27 & 5.61 & 0.0317 & \\
\hline $\mathrm{A}^{\wedge} 2$ & 15.74 & 1 & 15.74 & 38.97 & $<0.0001$ & \\
\hline $\mathrm{B}^{\wedge} 2$ & 79.74 & 1 & 79.74 & 197.44 & $<0.0001$ & \\
\hline $\mathrm{C}^{\wedge} 2$ & 8.15 & 1 & 8.15 & 20.17 & 0.0004 & \\
\hline $\mathrm{D}^{\wedge} 2$ & 0.34 & 1 & 0.34 & 0.84 & 0.3737 & \\
\hline Residual & 6.06 & 15 & 0.40 & & & \\
\hline Lack of Fit & 5.27 & 10 & 0.53 & 3.35 & 0.0972 & not significant \\
\hline Pure Error & 0.79 & 5 & 0.16 & & & \\
\hline Cor Total & 183.86 & 29 & & & & \\
\hline
\end{tabular}

Table 5:- ANOVA table for electrode melting rate

The anova table shows us the process parameters having the most significant influence on the weld penetration area the current and the gas flow rate is observed to have a very significant effect on the response with a p-value of $<0.0001$. To validate the adequacy of the quadratic model based on its ability to reduce the electrode melting rate the goodness of fit statistics presented in table 6

\begin{tabular}{|c|c|c|c|}
\hline Std. Dev. & 0.64 & R-Squared & 0.9671 \\
\hline Mean & 7.57 & Adj R-Squared & 0.9363 \\
\hline C.V. \% & 8.40 & Pred R-Squared & 0.8287 \\
\hline PRESS & 31.49 & Adeq Precision & 22.202 \\
\hline
\end{tabular}

Table 6:- GOF statistics for weld penetration area

The goodness of fit measures the strength and adequacy of the quadratic model. The results obtained shows that the model has $96 \%$ capacity to predict the weld penetration area when any change occurs in any of the input parameters. The optimal equation which shows the individual effects and combine interactions of the selected input variables (current, voltage,welding speed and gas flow rate) against the weld penetration area is presented based on the actual values in figure 1 


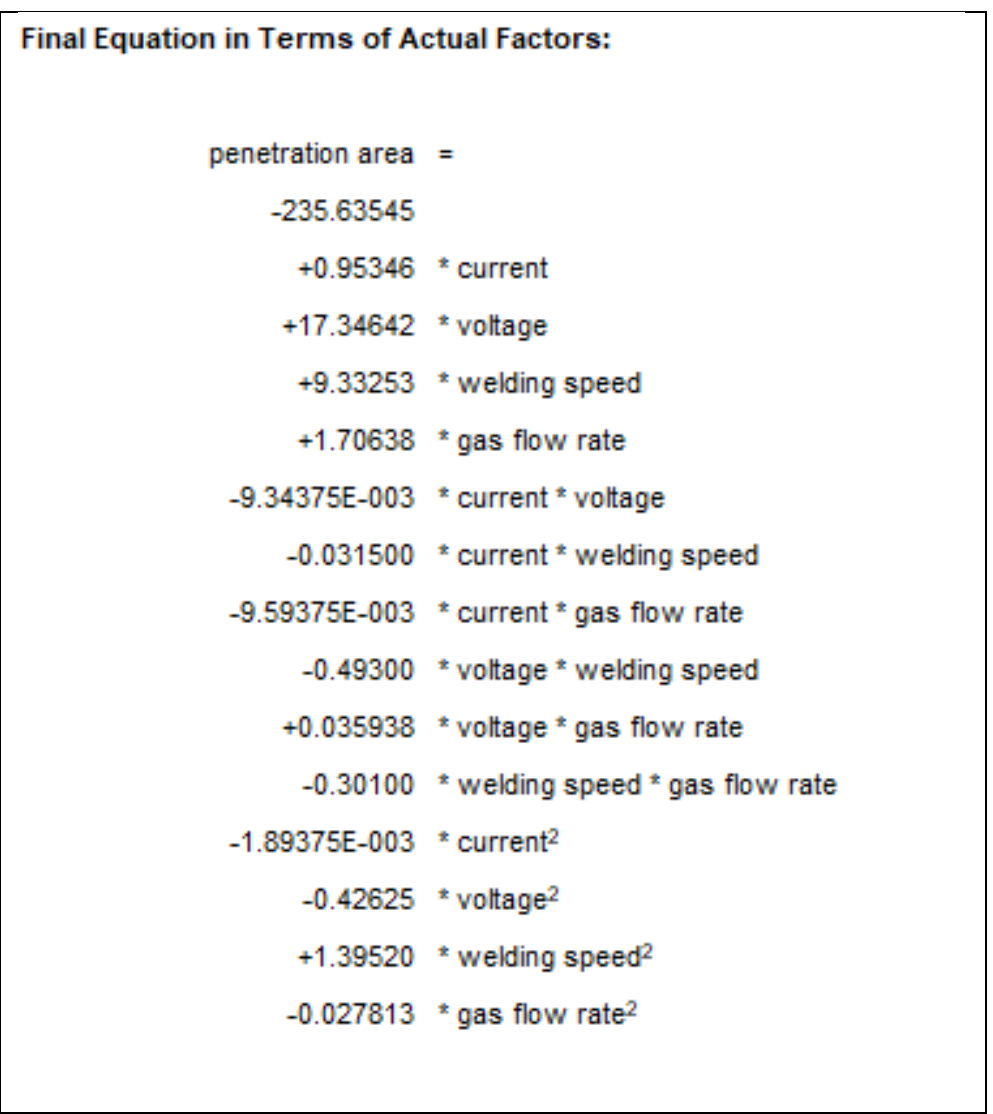

Fig 1:- optimal equation for weld penetration area

The response surface shows a 3D plot of the combined interaction between two input variables and the output To study the effects of current and voltage on weld penetration area, 3D surface plots presented in Figure 2 was generated as follows:
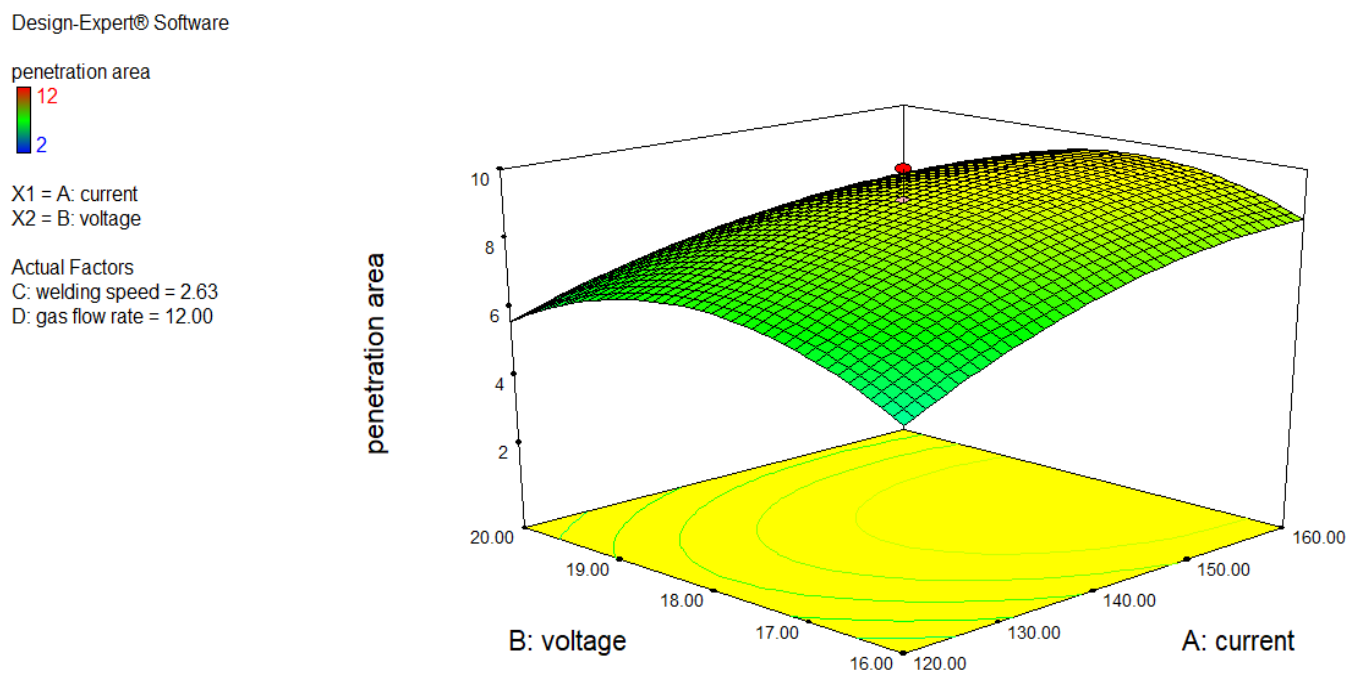

Fig 2:- Effect of current and voltage on penetration area

The figure above shows effects current and voltage has on the weld penetration area To study the effects of gas flow rate rate and current on the penetration area, 3D surface plots presented in Figure 3 was generated as follows: 

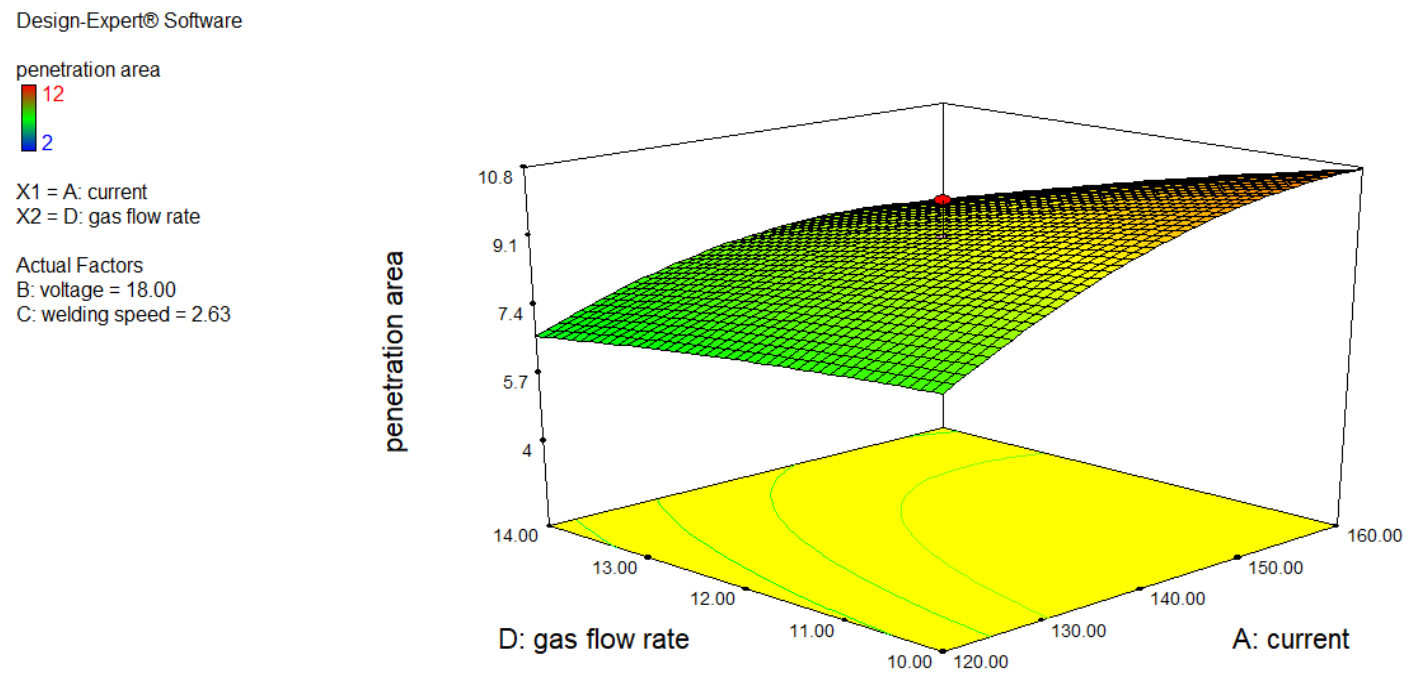

Fig 3:- Effect of wgas flow rate and current on penetration area

The surface plots in figure 2 and 3 shows that the combined interaction between current has a significant effect on the weld penetration area,an increase in current will lead to corresponding increase in the weld penetration area.The final numerical optimal solution was obtained showing optimal results for current, welding speed voltage, and gas flow rate that will produce maximum weld penetration area as shown in table 7

\begin{tabular}{|c|c|c|c|c|c|c|}
\hline Number & Current & voltage & $\begin{array}{c}\text { welding } \\
\text { speed }\end{array}$ & $\begin{array}{c}\text { gas flow } \\
\text { rate }\end{array}$ & penetration area & Desirability \\
\hline $\mathbf{1}$ & $\mathbf{1 5 9 . 5 7}$ & $\mathbf{1 7 . 7 5}$ & $\mathbf{2 . 0 0}$ & $\mathbf{1 1 . 3 1}$ & $\mathbf{1 0 . 9 4 9 9}$ & $\mathbf{0 . 8 2 4}$ \\
\hline 2 & 159.32 & 17.76 & 2.00 & 11.33 & 10.9416 & 0.824 \\
\hline 3 & 159.34 & 17.72 & 2.00 & 11.30 & 10.9475 & 0.824 \\
\hline 4 & 159.59 & 17.72 & 2.00 & 11.39 & 10.912 & 0.824 \\
\hline 5 & 160.00 & 17.77 & 2.00 & 11.39 & 10.9243 & 0.824 \\
\hline
\end{tabular}

Table 7:- Optimal solutions of numerical optimization model

\section{CONCLUSION}

In this study an approach using Response Surface Methodology to develop a mathematical model to maximize the weld penetration area in TIG welding has been achieved. The influence of current, voltage, welding speed and gas flow rate on the weld penetration area was investigated. The results obtained revealed that the second order quadratic polynomial equation is the best fit model that can accurately explain the effects of these input parameters on the penetration area. The results possessed good statistical sufficiency, having a very good coefficient of determination. The predicted $\mathrm{R}^{2}$ and the adjusted $\mathrm{R}^{2}$ are in reasonable agreement, surface plot showed the combined interaction of current, voltage and gas flow rate on the response, and ANOVA results revealed that the penetration area is very sensitive to the current parameter. The mathematical models developed has a high goodness of fit, adequate signal and strength which can explain and predict the relationship between the penetration area and the input parameters.

\section{REFERENCES}

[1]. Dongjie Li, Shanping Lu, Wenchao Dong, Dianzhiong Li, Yiyi Li. (2012). 6 Study of the law between the weld pool shape variations with the welding parameters under two TIG processes. Materials Procssing Technology, 128136. Examination Book of Specifications. (2008). American Welding Society.

[2]. Jung S.C, and Trang Y.S., Process Parameters Selection for Optimizing the Weld Pool Geometry in the Tungsten Inert Gas Welding of stainless Steel, Journal of Materials Processing Technology, 122, 2002, 33-37.

[3]. Odoemelam.C, Achebo.J.I,Ehiorobo.J.O, and Osaremwinda.J.O(2018)" $\quad$ Simulation-Based Optimization of Aspect Ratio in Tungsten Inert Gas Welding" scientific research publishing Engineering, 2018, 10, 876-890

[4]. Imhansoloeva.N.A, Achebo.J.I, Obahiagbon.K, Osarenmwinda.J.O, and Eruogun .C.E(2018)" Optimization of the Deposition Rate of Tungsten Inert Gas Mild Steel Using Response Surface Methodology" scientific research publishing Engineering, 2018, 10, 784-804 
[5]. Nweze .S and Achebo. J. I(2019)" Prediction of Weld Penetration Size Factor (WPSF) of TIG Mild Steel Weldment Using Fuzzy Logic" scientific research publishing Engineering, 2019, 11, 119-130

[6]. Owunna.I and Ikpe.A.E (2019)" Modelling and prediction of the mechanical properties of TIG welded joint for AISI 4130 low carbon steel plates using Artificial Neural Network (Ann) Approach" Nigerian Journal of Technology (NIJOTECH) Vol. 38, No. 1, January 2019, pp. 117 - 126 Copyright $($ F Faculty of Engineering, University of Nigeria, Nsukka, Print ISSN: 0331-8443, Electronic ISSN: 2467-8821

[7]. Pondi. P, Achebo .J and Obahiagbon .K (2017)" Optimization and Prediction of Ultimate Tensile of TIG Mild Steel Welds Using ANN "Industrial Engineering Letters www.iiste.org ISSN 2224-6096 (Paper) ISSN 2225-0581 (online) Vol.7, No.8, 2017 